\title{
AUTOPROMOCJA I BUDOWANIE MARKI OSOBISTEJ NA PORTALU INSTAGRAM NA TLE KULTURY NARCYZMU. ANALIZA ZJAWISKA NA PODSTAWIE BADANIA DZIESIĘCIU NAJPOPULARNIEJSZYCH PROFILI W SERWISIE
}

Abstract

SELF-REPRESENTATION AND BUILDING A PERSONAL BRAND ON THE INSTAGRAM PORTAL IN LIGHT OF THE CULTURE OF NARCISSISM AN ANALYSIS BASED ON A STUDY OF THE PORTAL'S TEN MOST POPULAR PROFILES

The aim of the present article is to analyse the mechanisms of self-representation and how the personal brand is being built by the Instagram users, with a particular emphasis on practices which fit into the culture of narcissism. The author uses qualitative methods based on a content analysis of Instagram profiles belonging to selected celebrities and celetoids. The group selection is intentional: the ten accounts which have been brought under study have the greatest number of followers according to the Social Blade rank. The author also reviews and analyses Polish and English literature on the phenomenon of Instagram, paying attention to its content and discussing research related to self-representation through this platform.

Key words: Instagram, new media, culture of narcissism, self-representation 


\section{Wstęp}

Zarówno tradycyjne, jak i nowe media znajdują się w fazie permanentnej zmiany, co wymusza nowe standardy działania i wysokie umiejętności aplikacyjne od nadawców, instytucji okołomedialnych, jak również indywidualnych użytkowników sieci. Bogusław Nierenberg pisze o widocznym wzroście znaczenia Internetu oraz urządzeń mobilnych, umożliwiających szybszą komunikację i korzystanie $\mathrm{z}$ wiadomości sieciowych ${ }^{1}$. Natomiast Tomasz Goban-Klas diagnozuje, iż współczesne media weszły w kolejne stadium mediamorfozy, cechującej się mobilnością medialną, gdzie telefon umożliwia zarówno odbiór, jak i nadawanie, stanowiąc hybrydę tych dwóch funkcji ${ }^{2}$. Badania naukowe w obszarze nauk o mediach pozostają również pod wpływem zachodzących zmian, a „pole badawcze w zakresie poznawania i diagnozowania zjawisk zachodzących w procesie komunikacji medialnej i szerzej - w sferze mediów - systematycznie się poszerza i przeżywa szczególny rozkwit"3. Stąd niezbędne wydaje się śledzenie i analizowanie nowych trendów, zjawisk oraz sposobów komunikacji.

Nowe media stały się nieodzownym elementem życia, stanowiąc doskonałą przestrzeń do autoprezentacji. Instagram, będący aplikacją mobilną do udostępniania zdjęć, umożliwiający poprawę ich wyglądu i dalsze dzielenie się nimi w różnych sieciach społecznościowych z przyjaciółmi, rodziną i zupełnie obcymi osoba$\mathrm{mi}$, stanowi doskonałe narzędzie do budowania własnego wizerunku $\mathrm{u}^{4}$. Ze względu na wizualny charakter aplikacji i zauważalny wysoki wskaźnik zaangażowania użytkowników Instagram jest także cennym narzędziem marketingowym w mediach społecznościowych. Warto zauważyć, że od marca 2016 roku aż 98 procent marek odzieżowych prowadzi swoje profile na Instagramie ${ }^{5}$. Yuheng Hu, Lydia Manikonda, Subbarao Kambhampati akcentują, że Instagram szczególnie zasługuje na uwagę społeczności naukowej, a jego analiza jest ważna, gdyż ukazuje głęboki wgląd $\mathrm{w}$ problemy społeczne, kulturowe i środowiskowe poprzez obiektyw zdjęć użytkowników, a sam obraz wart jest więcej niż tysiąc słów ${ }^{6}$.

${ }^{1}$ B. Nierenberg, Zarządzanie mediami. Ujęcie systemowe, Wydawnictwo Uniwersytetu Jagiellońskiego, Kraków 2013, s. 91-92.

2 T. Goban-Klas, Cywilizacja medialna. Geneza, ewolucja, eksplozja, Wydawnictwa Szkolne i Pedagogiczne, Warszawa 2005, s. 155-156.

${ }_{3}$ T. Sasińska-Klas, Swoistość zjawisk w komunikacji medialnej i problemy w ich badaniach empirycznych, „Studia Medioznawcze” 2014, nr 1 (56), s. 13.

${ }^{4}$ N. Hochman, R. Schwartz, Visualizing Instagram: Tracing Cultural Visual Rhythms, [w:] D. Archambault, E. Kandogan (eds.), AAAI Technical Report Social Media Visualization, The AAAI Press, Palo Alto 2012, s. 6.

${ }^{5}$ Number of Monthly Active Instagram Users from January 2013 to June 2018 (in Millions), The Statistical Portal, www.statista.com/statistics/253577/number-of-monthly-active-instagram-users/ (dostęp: 14.06.2018).

${ }_{6}$ Y. Hu, L. Manikonda, S. Kambhampati, What We Instagram: A First Analysis of Instagram Photo Content and User Types, [w:] E. Adar, P. Resnick (eds.), The Eighth International AAAI Conference on Weblogs and Social Media, The AAAI Press, Palo Alto 2014, s. 595. 
Przedmiotem badań w niniejszym artykule jest analiza sposobów autopromocji i budowania marek osobistych przez użytkowników portalu Instagram ze szczególnym uwzględnieniem praktyk wpisujących się w kulturę narcyzmu. Analiza osadzona jest w paradygmacie interpretatywnym, zgodnie z którym rzeczywistość nie ma charakteru konkretnego, lecz jest tworem intersubiektywnym jej uczestników, a rolę badacza stanowi zrozumienie, opis i interpretacja zjawisk społecznych ${ }^{7}$. W pracy zastosowane zostały metody jakościowe przy wykorzystaniu elementów analizy zawartości treści umieszczanych na profilach wybranych celebrytów i celetodiów. Dobór grupy jest celowy i obejmuje dziesięć kont, które według rankingu Social Blade posiadają najwięcej śledzących ich użytkowników ${ }^{8}$. Autorka dokonała również przeglądu i analizy literatury polskiej i anglojęzycznej dotyczącej zjawisk oraz fenomenów Instagramu, zwracając szczególną uwagę na treści i badania związane ze sztuką autoprezentacji za sprawą tej platformy. Warto w tym miejscu zaznaczyć, że chociaż opracowań dotyczących Instagramu wciąż przybywa, jest ich relatywnie niewiele, a wśród polskich przeważają te o charakterze poradnikowym.

\section{Instagram jako przedmiot badań}

Instagram, aplikacja przeznaczona na urządzenia mobilne i fotograficzny serwis społecznościowy hostingu zdjęć, posiada obecnie miliard aktywnych użytkowników ${ }^{9}$. To czyni ten założony w 2010 roku portal jednym z najpopularniejszych mediów społecznościowych na świecie. Jak możemy przeczytać w raporcie opracowanym przez The Statistical Portal, Instagram jest najpopularniejszy wśród nastolatków i młodych dorosłych, a 41 proc. jego użytkowników ma 24 lub mniej lat; Instagram wygrywa ranking popularności w tych kategoriach wiekowych w Stanach Zjednoczonych, pokonując tym sam Facebooka i Twittera ${ }^{10}$. Od 2012 roku właścicielem aplikacji i portalu społecznościowego jest Facebook ${ }^{11}$.

Przyczyną wysokiego zainteresowania wykorzystaniem Instagramu są jego parametry techniczne i cechy charakterystyczne wpływające na potencjał wykorzystania tej platformy do celów autopromocyjnych, m.in.:

${ }_{7}^{7}$ G. Burell, G. Morgan, Sociological Paradigms and Organizational Analysis, Heinemann, London 1979, s. 28.

${ }^{8}$ Top 100 Instagram Users by Followers, https://socialblade.com/instagram/top/100/followers, (dostęp: 10.06.2018).

9 D. Rosey, Instagram Reaches a Billion Users - and Other Things We Learnt from Boss Kevin Systrom, www.bbc.com/news/newsbeat-44553659 (dostęp: 20.06.2018).

${ }_{10}$ Number of Monthly Active..., dz. cyt.

11 K. Hill, 10 Reasons Why Facebook Bought Instagram, www.forbes.com/sites/kashmirhill/2012/04/11/ten-reasons-why-facebook-bought-instagram/\#4fed69c4d1b1 (dostęp: 10.07.2018). 
- bezpłatna aplikacja i ogólnodostępność;

- natychmiastowość zamieszczania treści;

- łatwość i intuicyjność obsługi;

- estetyczny interfejs;

- dostępność standardowych filtrów i narzędzi do modyfikacji zdjęć;

- aktualność relacji (można zamieszczać je tylko do 24 godzin od ich wykonania);

- możliwość dostępu do szerokiego grona odbiorców,

- agregacja treści z obserwowanych profili;

- interakcja ze społecznością;

- kategoryzacja materiału za pomocą hashtagów (\#);

- możliwość moderowania dostępu innych odbiorców do konta (ustawienia konta prywatnego i publicznego);

- możliwość powielenia zdjęcia i filmu na innych portalach społecznościowych (Facebook, Twitter, Tumblr);

- możliwość zamieszczania i targetowania reklam;

- nawiązywanie znajomości;

- możliwość ekspresji i wyrażania siebie poprzez obraz;

- modna platforma komunikacji ${ }^{12}$.

Instagram stanowi swoiste novum na rynku mediów społecznościowych, gdyż jest nastawiony głównie na komunikację wizualną za pomocą zdjęć i krótkich filmów. Wielu badaczy i obserwatorów mediów podkreśla wpływ tego portalu na zrewolucjonizowanie współczesnej fotografii. Możliwość powszechnie dostępnej fotografii wykonywanej dowolnemu obiektowi telefonem komórkowym stanowi nieodzowny element nowoczesnej epoki mediów społecznościowych ${ }^{13}$. Nieustająca sprawozdawczość, dokumentowanie wszelkich aktywności i wydarzeń stało się niemal nieodzownym elementem życia milionów ludzi na całym świecie. Można odnieść wrażenie, że jeżeli wydarzenie nie zostało uwiecznione na fotografii i udostępnione, to percepowane jest jako nierzeczywiste, pomimo racjonalnych przesłanek dotyczących jego natury ${ }^{14}$. Wojciech Engelking poddaje krytyce aktywność młodych użytkowników Instagramu, podkreślając, że uwieczniają wszystko, co tylko możliwe, a jego oburzenie budzą niestosowne relacje z wycieczek do miejsc zagłady ${ }^{15}$. W tym sensie fotografia stała się nie tylko zaświadczeniem o przeżyciu, lecz także środkiem rezygnacji z przeżyć, gdyż ludzie bardziej skupiają się na strategii wykonywania zdjęć niż doświadczeniu chwil ${ }^{16}$.

12 Por. S. Dunin-Wilczyński, Tradycyjne dziennikarstwo a Instagram, „Biuletyn Informacji” 2014, nr 1, s. 35-39; J. Drozdowicz, Decydujący moment w świecie Instagramu. Współczesna fotografia uliczna i wirtualne tożsamości, [w:] Z. Melosik, M.J. Szymański (red.), Tożsamość w warunkach zmiany społecznej, Wydawnictwo APS, Warszawa 2016, s. 227-237.

${ }^{13}$ J. Drozdowicz, Decydujący moment w świecie Instagramu..., dz. cyt., s. 231.

14 Tamże, s. 231.

15 W. Engelking, Instagram kiczu, Instagram zbrodni, „Nowe Media” 2014, nr 7/14, s. 89.

16 S. Sontag, O fotografii, tłum. S. Magala, Wydawnictwa Artystyczne i Filmowe, Warszawa 1986, s. 14. 
To, co cechuje cyberprzestrzeń, a tym samym świetnie oddaje specyfikę Instagramu, to fakt, iż wyobraźnia rekompensuje brak bodźców takich jak dotyk czy zapach, oraz angażowanie się użytkowników w ekscytujące interaktywne działanie, nieograniczony zasięg ${ }^{17}$, niskie koszty uczestnictwa, możliwa anonimowość, a zatem poczucie bezpieczeństwa ${ }^{18}$. Instagram daje szansę autoekspresji, a współczesna fotografia staje się narzędziem społecznej równości, każdy może wykonać zdjęcie i opublikować je w sieci. Z tego powodu badacze podejmują tematykę wpływu Instagramu na współczesną fotografię i kulturę obrazu, zwracając z jednej strony uwagę na pauperyzację fotografii, a $\mathrm{z}$ drugiej na możliwość wyzwolenia kreatywnego potencjału, o czym świadczą m.in. wystawy i konkursy instagramowej fotografii ${ }^{19}$.

Strona zapewnia użytkownikom natychmiastową możliwość uchwycenia i podzielenia się ważnymi momentami życia poprzez serię zdjęć w charakterystycznym kwadratowym kształcie oraz filmami, które również mogą podlegać edycji, jak również możliwość komentowania ${ }^{20}$. Natychmiastowe wysłanie przekazu, często emocjonalne, sprzyja jego ekspresyjności i ogranicza samotność jednostki ${ }^{21}$. Badania przeprowadzone przez Matthew Pittmana i Brandona Reicha sugerują, że wykorzystanie mediów społecznościowych opartych na obrazie może mieć istotny wpływ na uczucia i postawy jednostek - samotność może się zmniejszyć, natomiast szczęście i zadowolenie z życia wzrosnąć - oczywiście w zależności od sposobów ich wykorzystania. Badacze zauważają, że efekt ten może mieć związek z większą intymnością, którą oferują media oparte na komunikacji wizualnej (w porównaniu do opartych na tekście $)^{22}$.

Niewątpliwie jednak ważkim problemem, który pojawia się w dyskursie naukowym, jest wpływ tej platformy na kwestię zaburzeń zachowań i postrzegania rzeczywistości przez młodych użytkowników. Istotnym aspektem oddziaływań społecznych zmanipulowanych zdjęć z Instagramu staje się zaburzenie postrzegania ciała. Badania odbioru oryginalnych i zretuszowanych zdjęć z portalu przeprowadzone przez Mariskę Kleemans, Serenę Daalmans, Ilanę Carbaat i Doeschkę Anschütz pokazały, że zmanipulowane zdjęcia zostały lepiej ocenione przez dziewczyny w wieku 14-18 lat niż oryginalne zdjęcia, pomimo wykrycia filtrów i dodatkowych efektów. Ponadto zdjęcia te zostały przez badane ocenione jako realistyczne i prawdziwe $e^{23}$. Joanna Bierówka zwraca uwagę, że ponowoczesne społeczeństwo ryzyka i permanentnej zmiany może być dla jednostki źródłem cierpień i traumy,

17 J. Kreft, Ewolucja strategii transmedialnych korporacji transnarodowych, Wydawnictwo Uniwersytetu Gdańskiego, Gdańsk 2012, s. 108.

18 S.K. Kacprzyk, R. Leppert, Związki miłosne w sieci, Impuls, Kraków 2013, s. 16-17.

19 Zob. J. Drozdowicz, Decydujący..., dz. cyt., s. 227-237.

${ }^{20}$ S. Dunin-Wilczyński, Tradycyjne dziennikarstwo a Instagram, dz. cyt., s. 33-34.

${ }^{21}$ T. Goban-Klas, Cywilizacja..., dz. cyt., s. 157.

${ }^{22}$ M. Pittman, B. Reich, Social Media and Loneliness: Why an Instagram Picture May Be Worth More than a Thousand Twitter Words, „Computers in Human Behavior” 2016, nr 62, s. 155-167.

${ }^{23}$ M. Kleemans, S. Daalmans, I. Carbaat, D.J. Anschutz, Picture Perfect: The Direct Effect of Manipulated Instagram Photos on Body Image in Adolescent Girls, „,Media Psychology” 2018, nr 21, s. 93. 
stosuje się więc strategie adaptacyjne umożliwiające oswojenie lęku przed samotnością i niepewnością, czego przykładem jest tworzenie grup wsparcia dla ludzi z różnymi zaburzeniami, propagującymi te idee ${ }^{24}$. Podobnie Marika Tiggemann i Mia Zaccardo, analizując zdjęcia wpisujące się w trend fitspiration, mający propagować zdrowy styl życia i uprawianie sportu, zaobserwowały, że w rzeczywistości lansuje on kobiety o nadmiernie szczupłej budowie ciała, co może wpływać na negatywne postrzeganie siebie u innych użytkowników ${ }^{25}$.

\section{Instagram jako medium narcystyczne}

Tara M. Dumas, Matthew Maxwell-Smith, Jordan P. Davis i Paul A. Giulietti zbadali, iż istnieje silna korelacja pomiędzy narcyzmem a zwodniczym poszukiwaniem pozytywnego odbioru, co stanowi dla wielu użytkowników motywację do korzystania z Instagramu, dając przede wszystkim szansę na zwiększenie popularności i pokazanie własnej kreatywności ${ }^{26}$. Podobnie Magdalena Szpunar akcentuje, że narcyzm jest jednym z najbardziej eksponowanych zjawisk, dostrzegalnych w sferze nowomedialnej aktywności użytkowników sieci:

Internet jest medium narcystycznym, umożliwiającym erupcję zachowań skierowanych na własne ja. Dziesiątki aplikacji służą wielu celom, ale przede wszystkim wspierają celebrowanie samego siebie. Medium to jak żadne inne wzmacnia i podtrzymuje narcystyczne inklinacje jednostek, sprawiając, że kluczowa staje się autoprezentacja i odpowiednio spreparowana kreacja samego siebie. Intensyfikując niezwykle wyraźne tendencje kultury opartej o wizualność, staje się źródłem epidemii narcyzmu ${ }^{27}$.

Instagram stanowi egzemplifikację medium nastawionego na kreację jednostki poprzez zamieszczanie wybranych i zmodyfikowanych zdjęć, dając ku temu proste narzędzia i możliwości techniczne. Christopher Lasch, autor terminu kultury narcyzmu w odniesieniu do analizy konsumpcyjnego społeczeństwa amerykańskiego, pisze, iż współczesne media wzmacniają narcystyczne marzenia jednostek o sławie i rozgłosie, tym samym zachęcając przeciętnego człowieka do utożsamiania się z gwiazdami ${ }^{28}$. Sam termin "narcyzm” wywodzi się z mitu o Narcyzie, pięknym

${ }^{24}$ J. Bierówka, Społeczności sieciowe propagujące anoreksje jako przykład zbiorowego eskapizmu, [w:] P. Francus, S. Jędrzejewski (red.), Nowe media i komunikowanie wizualne, Katolicki Uniwersytet Lubelski, Lublin 2010, s. 173.

${ }_{25}$ M. Tiggemann, M. Zaccardo, Strong Is the New Skinny: A Content Analysis of \#fitspiration Images on Instagram, „Journal of Health Psychology” 2016, nr 23(8), s. 1003-1011.

${ }^{26}$ T.M. Dumas, M. Maxwell-Smith, J.P. Davis, P.A. Giulietti, Lying or Longing for Likes? Narcissism, Peer Belonging, Loneliness and Normative versus Deceptive Like-Seeking on Instagram in Emerging Adulthood, „Computers in Human Behavior” 2017, nr 71, s. 10.

${ }_{27}$ M. Szpunar, Kultura cyfrowego narcyzmu, Wydawnictwa AGH, Kraków 2016, s. 146.

${ }^{28}$ C. Lasch, Kultura narcyzmu. Amerykańskie życie w czasach malejących oczekiwań, tłum. G. Ptaszek, A. Skrzypek, Wydawnictwo Akademickie SEDNO, Warszawa 2015, s. 48. 
młodzieńcu, który widząc własne odbicie w tafli wody, zakochał się w nim ${ }^{29}$. Wersji tego mitu jest wiele, jednak niezależnie od przyjętego wariantu postać Narcyza jest uosobieniem niedojrzałości, egoizmu, skupienia na samym sobie oraz nieumiejętności obdarzania uczuciem innych. Narcyz w swojej miłości pozostaje jedynie na poziomie zmysłu wzroku ${ }^{30}$. Przyjmuje obraz, który wykreował, za prawdziwy. Tworząc wyimaginowany obraz siebie, „nurza się we własnym odbiciu”, nie rozumiejąc, że to jedynie tylko jego własne odbicie ${ }^{31}$.

Magdalena Szpunar zauważa, że znaczącym determinantem mającym wpływ na zjawisko cyfrowego narcyzmu jest silna konkurencyjność i presja sukcesu, które powodują u ludzi obsesyjną potrzebę sławy, a do tego kariery celebrytów wskazują, że taką medialną sławę można uzyskać bez żadnych wyjątkowych kompetencji czy umiejętności, lecz stosując odpowiednie techniki autopromocji. Szpunar konstatuje: „Internet pozwala w łatwy sposób upozorować status celebryty, oferując szybką sławę instant" 32 .

Yuheng $\mathrm{Hu}$, Lydia Manikonda i Subbarao Kambhampati na podstawie analizy zawartości Instagramu wydzielili następujące rodzaje najczęściej publikowanych zdjęć: selfie (autoportrety), znajomi, zajęcia (aktywność sportowa, spędzanie wolnego czasu), napisy (zdjęcia z wbudowanym tekstem), jedzenie (napoje, potrawy, przepisy kulinarne), gadżety (elektroniczne, motoryzacyjne), moda (ubrania, buty, stylizacje, make-up) i zwierzęta domowe. Wskazali, że najpopularniejszych jest sześć pierwszych typów ${ }^{33}$.

Natomiast badania przeprowadzone przez Jang Ho Moon, Eunji Lee, Jung-Ah Lee, Tae Rang Choi i Yongjun Sung wykazały, iż osoby z wyższym poziomem narcyzmu częściej zamieszczały na swoich profilach selfie i prezentowały własne zdjęcia, częściej aktualizowały również zdjęcia profilowe i spędzały więcej czasu na Instagramie w porównaniu do grupy kontrolnej ${ }^{34}$. Dzielenie się selfies $\mathrm{w}$ mediach społecznościowych stało się popularnym działaniem, skłaniającym do pytań o jego znaczenie psychologiczne i motywy o charakterze dyspozycyjnym ${ }^{35}$.

Selfie stało się integralną częścią życia towarzyskiego w mediach społecznościowych, zwłaszcza na Instagramie ${ }^{36}$. Sejung Marina Choi w swoich badaniach zidentyfikowali motywacje, które stymulują autopostrzeganie oraz skłaniają ludzi

${ }^{29}$ C. Dziekanowski, Klątwa Narcyza, [w:] J. Sieradzan (red.), Narcyzm, Wydawnictwo Uniwersytetu w Białymstoku, Białystok 2011, s. 326.

${ }^{30}$ K. Zimek, Miłość cienia: interpretacja mitu o Narcyzie w erotyku „Do Kasie” i rękopisu Zamoyskiego, „Pamiętnik Literacki” 2003, nr 94/4, s. 12.

${ }^{31}$ C. Lasch, Kultura narcyzmu..., dz. cyt., s. 263.

${ }_{32}$ M. Szpunar, Imperializm kulturowy internetu, Instytut Dziennikarstwa, Mediów i Komunikacji Społecznej Uniwersytetu Jagiellońskiego, Kraków 2017, s. 101.

${ }_{33}$ Y. Hu, L. Manikonda, S. Kambhampati, What We Instagram..., dz. cyt. s. 597-598.

${ }^{34}$ J. Ho Moon, E. Lee, J.A. Lee, T.R. Choi, Y. Sung, The Role of Narcissism in Self-Promotion on Instagram, „Personality and Individual Differences” 2016, nr 101, s. 22-25.

35 E.B. Weiser, \#Me: Narcissism and Its Facets as Predictors of Selfie-Posting Frequency, „Personality and Individual Differences" 2015, nr 86, s. 477.

${ }^{36}$ T. Thumin, Self-Represtation and Digital Culture, Palgrave Macmillan, Basingstoke 2015, s. 142. 
do dzielenia się z innymi swoimi autoportretami. Wynikiem ich badań jest wydzielenie czterech motywacji skłaniających użytkowników do zamieszczania selfies w mediach społecznościowych: (1) poszukiwanie uwagi, (2) komunikacja, (3) archiwizacja, (4) rozrywka ${ }^{37}$. Badacze zauważyli ponadto, iż wykazywanie cech narcystycznych przez jednostkę w znaczących stopniu wpływało na intencję oraz częstotliwość autoportretowania ${ }^{38}$.

Saeideh Bakhshi, David A. Shamma i Eric Gilbert zaobserwowali, że zdjęcia przedstawiające twarze posiadają o $38 \%$ większe prawdopodobieństwo, iż zostaną "polubione”, jest również o 32\% bardziej prawdopodobne, że zostaną skomentowane ${ }^{39}$. Ponadto ich wyniki pokazują, że liczba twarzy na zdjęciu, wiek i płeć nie mają $\mathrm{w}$ tym procesie większego znaczenia. Olbrzymie oddziaływanie zjawiska selfie pokazuje konsekwencje zmiany kultury globalnej, uosabiającej celebrację „,skrajnego indywidualizmu w postaci narcystycznie eksponowanego ego" ${ }^{\prime 4}$. Selfie stawia "ja" w centrum uwagi, czyniąc $z$ innych jedynie tło $^{41}$. Jest najwyższym poziomem egzemplifikacji współczesnej autoreprezentacji ${ }^{42}$. Obraz jednostki i sposoby jej autoprezentacji stają się jednymi z najważniejszych cech zorientowanej narcystycznie kultury, w której „na pierwszy plan wysuwa się prezencja, dbałość o własną fizys i społeczny odbiór" ${ }^{\prime 3}$. Magdalena Szpunar łączy to ze zjawiskiem hiperobecności, ciągłej walki o uwagę i nadmiarowej produkcji informacji na własny temat, co ma za zadanie zapewnienie użytkownikowi rozpoznawalności w sieci ${ }^{44}$.

\section{Sposoby autoprezentacji oraz promocji na Instagramie - wnioski z badań}

Na potrzeby niniejszego artykułu autorka przeanalizowała tygodniową aktywność ( $w$ terminie od 24.06 do 1.07.2018 r.) dziesięciu najpopularniejszych kont na Instagramie. Badanie miało charakter pilotażowy, polegało na analizie zdjęć i ich opisów zamieszczonych na portalu, kategoryzacji zdjęcia pod względem rodzaju i tematu, sposobów autopromocji i odbioru treści przez innych użytkowników, a następnie konfrontacji wyników z literaturą przedmiotu. Do określenia rodzaju zdjęcia

${ }^{37}$ Y. Sung, J.A. Lee, E. Kim, S.M. Choi, Why We Post Selfies: Understanding Motivations for Posting Pictures of Oneself, „Personality and Individual Differences” 2016, nr 97, s. 260-265.

38 Tamże.

39 S. Bakhshi, D.A. Shamma, E. Gilbert, Faces Engage Us: Photos with Faces Attract More Likes and Comments on Instagram, CHI 2014, One of a CHInd, Toronto 2014, s. 972-973.

${ }^{40}$ J. Drozdowicz, Decydujący moment..., dz. cyt., s. 233.

${ }^{41}$ Tamże, s. 233.

${ }^{42}$ N. Thumin, Self-Represtation..., dz. cyt., s. IX.

${ }_{43}$ M. Szpunar, Imperializm..., dz. cyt., s. 97.

${ }^{44}$ M. Szpunar, Medialna widoczność jako emanacja hiperobecności, „Zeszyty Prasoznawcze” 2017, nr 3 (231), s. 496. 
autorka posłużyła się typologią zaproponowaną przez Yuheng Hu, Lydię Manikonda i Subbarao Kambhampati ${ }^{45}$, proponując również nowe kategorie. W tabeli 1. zaprezentowano wykaz profili, które poddane były analizie, wraz z liczbą osób śledzących oraz wszystkich postów, a także postów zamieszczonych w analizowanym okresie. W tabeli 2. zaprezentowano natomiast rodzaj, tematykę oraz odbiór postów na podstawie badań własnych.

Tabela 1. Wykaz najpopularniejszych kont na Instagramie (stan na 2.07.2018)

\begin{tabular}{|c|c|c|c|c|}
\hline Lp. & Nazwa konta & Właściciel & Liczba postów & $\begin{array}{c}\text { Liczba } \\
\text { obserwatorów }\end{array}$ \\
\hline 1. & instagram & Serwis Instagram, konto firmowe & 5317 & $241 \mathrm{mln}$ \\
\hline 2. & selenagomez & Selena Gomez & 1442 & $138 \mathrm{mln}$ \\
\hline 3. & cristiano & Cristiano Ronaldo & 2296 & $132 \mathrm{mln}$ \\
\hline 4. & arianagrande & Ariana Grande & 3493 & $122 \mathrm{mln}$ \\
\hline 5 . & beyonce & Beyoncé Knowles & 1634 & $115 \mathrm{mln}$ \\
\hline 6. & kimkardashian & Kim Kardashian West & 4403 & $113 \mathrm{mln}$ \\
\hline 7. & kyliejenner & Kylie Jenner & 5504 & $110 \mathrm{mln}$ \\
\hline 8. & taylorswift & Taylor Swift & 188 & $109 \mathrm{mln}$ \\
\hline 9. & therock & Dwayne D. Johnson & 3650 & $109 \mathrm{mln}$ \\
\hline 10. & justinbieber & Justin Bieber & 4357 & $100 \mathrm{mln}$ \\
\hline
\end{tabular}

Źródło: https://socialblade.com/youtube/top, Instagram.com.

Najpopularniejszym kontem w badanym serwisie jest profil firmowy Instagramu, będący w analizowanym zestawieniu jedynym kontem, które nie jest poświęcone konkretnej osobie. W rankingu najpopularniejszych kont znajdują się konta piosenkarzy (Selena Gomez, Arianna Grande, Beyoncé, Taylor Swift, Justin Bieber), sportowców (piłkarz Cristiano Ronaldo, zapaśnik i aktor Dwayne D. Johnson) oraz celebrytów (Kim Kardashian i Kylie Jenner).

Badanie pokazuje różną aktywność i częstotliwość w publikowaniu materiałów na Instagramie. Najczęściej jest to kilka do kilkunastu postów, wyjątek stanowi Selena Gomez, która w badanym okresie nie opublikowała żadnego postu, co wynika $\mathrm{z}$ faktu, że piosenkarka publikuje treści w portalu nieregularnie. W tabeli 2. zaprezentowano kategoryzację rodzajów i tematyki zdjęć, co potwierdza typologię zaproponowaną przez Yuheng Hu, Lydię Manikonda i Subbarao Kambhampati,

${ }^{45}$ Kategorie selfie takie jak: znajomi, zajęcia (aktywność sportowa, spędzanie wolnego czasu), napisy (zdjęcia z wbudowanym tekstem), jedzenie (napoje, potrawy, przepisy), gadżety (elektroniczne, motoryzacyjne), moda (ubrania, buty, stylizacje, make-up) i zwierzęta domowe. Por. L. Hu, Manikonda, S. Kambhampati, What We Instagram..., dz. cyt., s. 597-598. 


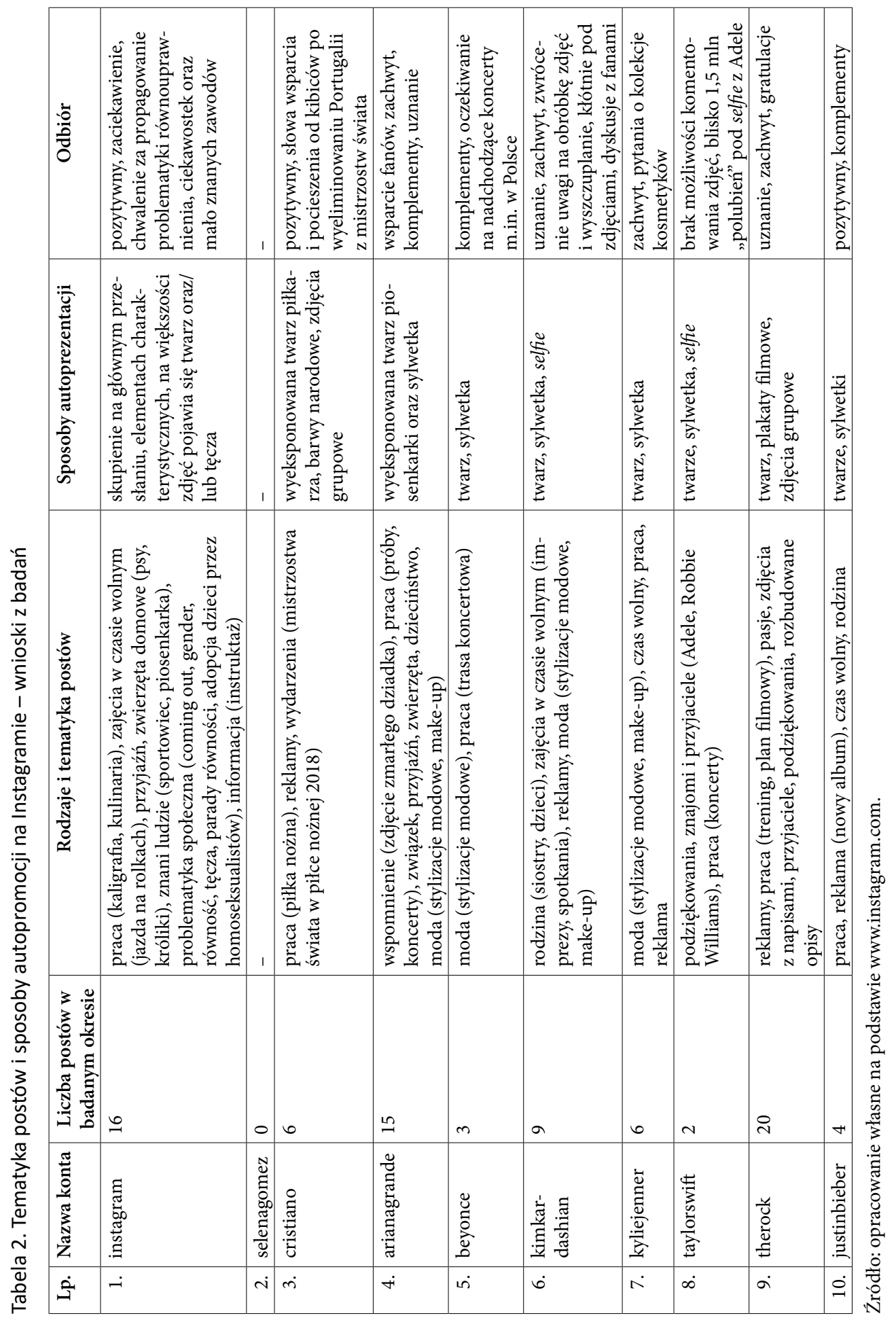


jak również wskazuje kolejne istotne kategorie zdjęć, takie jak propagowanie kampanii i akcji społecznych, co szczególnie widać na profilu firmowym Instagramu, a także reklamy i lokowanie produktu oraz materiały o charakterze wspomnieniowym (z dzieciństwa, posty o zmarłych bliskich). Warto także sprecyzować kategorię Znajomi, gdyż dopiero analiza kontekstu i opisu wskazuje, że oprócz przyjaciół na zdjęciach pojawiają się rodzina i partnerzy. Celebryci zamieszczają fotografie z produktami, których są przedstawicielami, właścicielami lub promują je $\mathrm{w}$ ramach kontraktów reklamowych - Kylie Jenner reklamuje własną linię kosmetyków, Justin Bieber nową płytę, Ronaldo buty Nike, a Kim Kardashian kremy marki Olay.

Wśród zdjęć dominują te $\mathrm{z}$ twarzami i sylwetkami celebrytów, pokazujących swoje życie zarówno zawodowe, jak i osobiste. Często też fotografują się z innymi znanymi osobami, co zyskuje uznanie fanów, np. Taylor Swift zamieściła selfie z Adele, Ronaldo z innymi piłkarzami reprezentacji Portugalii, a Kim Kardashian z siostrami celebrytkami. Koresponduje to z obserwacjami Wiesława Godzica, który twierdzi, że paradoksalnie celebryci nie są nastawieni na konkurencję, lecz lubią fotografować się ze znanymi osobami, natomiast ludzie czerpią przyjemność $\mathrm{z}$ takiego podglądania ${ }^{46}$. Każde $\mathrm{z}$ zamieszczonych zdjęć na badanym portalu jest starannie opracowane zarówno pod względem kompozycji, jak i wyglądu prezentowanych osób, które jawią się jako atrakcyjne, zadbane, szczupłe i starannie wystylizowane, tym samym wpisujące się w kulturę narcyzmu. Widać to zwłaszcza na portalu Christiana Ronaldo, Kim Kardashian West oraz Kylie Jenner. Pod zamieszczonym w serwisie selfie Kim Kardashian pozującej w garderobie w samej bieliźnie, rozpętała się dyskusja na temat retuszu zdjęcia, w której część obserwatorów dowodziła, że talia celebrytki została zwężona, a tło nienaturalnie zakrzywione. Sama zainteresowana nie odniosła się do tej kwestii.

Analiza komentarzy wskazuje na istnienie więzi użytkowników Instagramu z celebrytami, dominuje pozytywny odbiór zamieszczanych treści, a nawet wyznawanie miłości (np. na kontach Arianny Grande, Kim Kardashian West). Wcześniejsze więzi wpływają na przychylne reakcje użytkowników na kolejne komunikaty dostarczane przez tę samą osobę ${ }^{47}$. W takich warunkach wytwarzają się relacje paraspołeczne, emocjonalne więzi ze znanym z sieci osobami; odbiorcy mają iluzję obcowania $\mathrm{z}$ nimi twarzą w twarz, co nasila się, gdy ogląda się ich regularnie i zaczyna traktować jak własnych znajomych ${ }^{48}$. Zbigniew Bauman zauważał, że poczucie tożsamości jednostki może powstać tylko dzięki długotrwałym i godnym zaufania więziom łączącym ją z innymi. Współcześnie ludzie poszukują środków

${ }^{46}$ W. Godzic, Znani z tego, że sa znani. Celebryci w kulturze tabloidów, Wydawnictwa Akademickie i Profesjonalne, Warszawa 2007, s. 48.

${ }^{47}$ K. Michalewski, Autoprezentacja i prezentacja w mediach, [w:] B. Kudra, E. Olejniczak (red.), Komunikowanie publiczne. Zagadnienia wybrane, Wydawnictwo Uniwersytetu Łódzkiego, Łódź 2014, s. 75.

${ }^{48}$ P. Szarota, Od Facebooka do post-przyjaźni, Instytut Psychologii. Polska Akademia Nauk, Warszawa 2018, s. 108-109. 
zastępczych, zamieniając niewielką liczbę pogłębionych relacji na dużą płytkich i tanich kontaktów, będących jedynie surogatami ${ }^{49}$.

Według Guya Kawasaki i Peg Fitzpatrick skuteczna strategia autopromocyjna na Instagramie cechuje się prostotą przekazu, zwięzłością opisu, dobraniem popularnych hashtagów, a przede wszystkim na opowiadaniu jakiejś historii ${ }^{50}$. Strategię tę widać na badanych profilach. Beyoncé pozuje w samolocie w drodze na koncert do Polski, co podgrzewa atmosferę oczekujących na nią fanów, którzy wyrażają to w komentarzach. Kim Kardashian i Kylie Jenner ukazują, że miło spędzają czas w gronie rodziny, na co znajdują czas po pracy i sesjach zdjęciowych, których kulisy stale relacjonują. Podobnie Justin Bieber kreuje się na rodzinną osobę, zamieszczając zdjęcia brata; Arianna Grande publikuje czarno-białe zdjęcie zmarłego dziadka. Świadomie budują tożsamość marki, dbając o jej spójność i logiczność przekazów. Tym samym zarządzają własną marką, budując popularność i podnosząc jej wartość w czasie. Tworząc trendy, stanowią także wzór dla innych użytkowników Instagramu, którzy szukają inspiracji dla własnej aktywności ${ }^{51}$.

Autoprezentacja jest umiejętnością zarządzania wrażeniami, kontroli tego, jak inni postrzegają daną osobę ${ }^{52}$. Każdy z badanych celebrytów kształtuje własną markę osobistą, będącą pewną personifikacją wartości i kompetencji uosabianych przez tę jednostkę. Poprzez formułowanie przekazu i autoprezentację wpływa na swój wizerunek i oddziałuje na to, jak postrzegają go inni i jakie cechy mu przypisują. Budowanie marki osobistej uwydatnia atuty, cechy wartościowe dla odbiorców, ale przede wszystkim utrwala w ich pamięci pożądany obraz danej jednostki ${ }^{53}$. Badani celebryci skupiają się na budowaniu rozpoznawalności, reputacji, zdobyciu coraz szerszej grupy odbiorców. Dostosowują się do zmian kulturowych, skupiają na komunikacji wizualnej, aby nie utracić konkurencyjności ${ }^{54}$. Współczesne marki osobiste zawierają w sobie dwa wymiary: zarówno fizyczny (realny człowiek), jak i wirtualny (kreowany w Internecie, dostępny, publiczny, niekoniecznie prawdziwy) ${ }^{55}$. Ten ostatni nieustannie zyskuje na znaczeniu i pozwala dotrzeć do coraz szerszej grupy odbiorców. Obejmuje również znaczenia symboliczne - korzyści, wartości, osobowość i kulturę ${ }^{56}$.

${ }^{49}$ Z. Bauman, Tożsamość. Rozmowy z Benedetto Vecchim, tłum. J. Łaszcz, GWP, Gdańsk 2004, s. $65-66$.

${ }^{50}$ Zob. G. Kawasaki, P. Fitzpatrick, Jak cię widza, tak cię piszą. Sztuka autopromocji w mediach społecznościowych, tłum. M. Gutowski, Helion, Gliwice 2016.

${ }_{51}$ P. Czarnota, Wykorzystanie portalu społecznego Instagram $w$ działaniach promocyjnych przedsiębiorstw, „Zeszyty Naukowe Politechniki Częstochowskiej. Zarządzanie” 2017, nr 25, s. 136.

${ }^{52}$ G. Królik, Autoprezentacja, Wydawnictwo Akademii Ekonomicznej, Katowice 2002, s. 9.

${ }_{53}$ M. Gawanowska, Marka osobista bez tajemnic, Monika Gawanowska Copyright, Białystok 2017, s. 23.

${ }^{54}$ R. Stępowski, Jak osiagnąc sukces. Jak zbudować swoją markę osobistą i sprawić, by firma osiągnęła sukces, Wydawnictwo Roster, Rawa Mazowiecka 2015, s. 58.

${ }_{55}$ M. Gawanowska, Marka..., dz. cyt., s. 29.

56 A. Bruszko, BrandU. Czyli nowa marka o nazwie TY, Wydawnictwo Poligraf, Brzezia Łąka 2017, s. 9. 


\section{Podsumowanie}

Udostępnianie fotografii $\mathrm{w}$ różnych serwisach społecznościowych stało się ważnym elementem społecznego doświadczenia. Sukces Instagramu, przejawiający się w miliardzie aktywnych użytkowników miesięcznie, potwierdza fakt, że zdjęcia i filmy stały się kluczowymi walutami społeczności online ${ }^{57}$. Użytkownicy mediów społecznościowych korzystają z różnego rodzaju zdjęć, często z autoportretów, aby pokazać swoją osobowość, własny styl życia i osobiste preferencje. Celebryci sprawnie wykorzystują możliwość wizualnych form komunikacji, budując swoją popularność i markę osobistą, co przekłada się także na kontrakty reklamowe i promocję innych marek, spójnych z ich wizerunkiem. Popularność wykorzystywana jest także przez administratorów kont do propagowania akcji społecznych i walki z różnorakimi przejawami dyskryminacji, co widać zwłaszcza na profilu firmowym Instagramu.

Determinantami przyczyniającymi się do sukcesu badanych marek osobistych na Instagramie są niewątpliwie: spójność przekazu, świadomość procesu budowania marki, przemyślane działanie, opowiadanie historii, budowanie poczucia autentyczności i zaangażowania użytkowników, dostępność zasobów ${ }^{58}$. Pilotażowe badania aktywności dziesięciu najpopularniejszych profili na Instagramie wykazały, że treści są ukierunkowane na prostotę przekazu, jej wizualny charakter, a zdjęcia są estetyzowane, ukazują celebrytów jako atrakcyjnych, młodych, wysportowanych, bogatych, kreatywnych ludzi, posiadających ciekawe życie zawodowe i osobiste, co wpisuje się w cechy kultury narcyzmu.

Aktywność $\mathrm{w}$ mediach społecznościowych ma zarówno pozytywne, jak i negatywne aspekty ${ }^{59}$. Za pomocą Instagramu i podobnych form przekazu nie da powiedzieć się zbyt wiele, komunikacja staje się powierzchowna ${ }^{60}$. $Z$ jednej strony interaktywność, uniwersalność, powszechna dostępność do przekazu i globalna hiperrealność dają użytkownikom poczucie indywidualności i wyjątkowości, czego nie zapewniały media $\mathrm{XX}$ wieku ${ }^{61}$. Nie mamy jednak do czynienia $\mathrm{z}$ radykalnym i zupełnym zerwaniem z przeszłością, lecz z pewnym continuum, ukazującym nieustanny proces ewolucji mediów. Media podlegają bowiem nieustanemu procesowi wzajemnego oddziaływania na siebie i reprodukcji, wypełniają braki lub poprawiają błędy poprzednich form przekazu, co stanowi istotę procesu remediacji ${ }^{62}$. $\mathrm{Z}$ dru-

${ }^{57}$ L. Rainie, J. Brenner, K. Purcell, Photos and Videos as Social Currency Online, www.pewinternet.org/2012/09/13/photos-and-videos-as-social-currency-online/ (dostęp: 10.07.2018).

${ }_{58}$ Por. M. Gawanowska, Marka..., dz. cyt., s. 37-66.

${ }^{59}$ J. Mierzwa, H. Jurjewicz, Does Facebook, Twitter, Instagram Influence Well-Being and Self-Esteem among Early Adolescents?, „Studia Socialia Cracoviensia” 2016, nr 1(14), s. 150.

${ }^{60}$ N. Chomsky, The Universal Man, „New Scientists” 2012, nr 213, s. 29.

${ }^{61}$ P. Barczyk, Nowe technologie a kultura cyfrowego dostępu, [w:] B. Jung (red.), Wokół mediów ery Web 2.0, Wydawnictwa Akademickie i Profesjonalne, Warszawa 2010, s. 28.

62 Por. J. Bolter, R. Grusin, Remediation: Understanding New Media, The MIT Press, London 2000. 
giej strony media społecznościowe, a w tym Instagram, kształtują trendy, promują zachowania narcystyczne, często prowadzą do manipulowania i zakłamywania rzeczywistości, co przekłada się na zaburzenia postrzegania siebie przez użytkowników sieci63.

\section{Bibliografia}

Bakhshi S., Shamma D.A., Gilbert E., Faces Engage Us: Photos with Faces Attract More Likes and Comments on Instagram, CHI 2014, One of a CHInd, Toronto 2014, s. 965-974.

Barczyk P., Nowe technologie a kultura cyfrowego dostępu, [w:] B. Jung (red.), Wokół mediów ery Web 2.0, Wydawnictwa Akademickie i Profesjonalne, Warszawa 2010, s. 10-31.

Bauman Z., Tożsamość. Rozmowy z Benedetto Vecchim, tłum. J. Łaszcz, GWP, Gdańsk 2004.

Bierówka J., Społeczności sieciowe propagujące anoreksje jako przykład zbiorowego eskapizmu, [w:] P. Francus, S. Jędrzejewski (red.), Nowe media i komunikowanie wizualne, Katolicki Uniwersytet Lubelski, Lublin 2010, s. 173-184.

Bolter J., Grusin R., Remediation: Understanding New Media, The MIT Press, London 2000.

Czarnota P., Wykorzystanie portalu społecznego Instagram $w$ działaniach promocyjnych przedsiębiorstw, „Zeszyty Naukowe Politechniki Częstochowskiej. Zarządzanie” 2017, nr 25, s. $130-139$.

Bruszko A., BrandU, czyli nowa marka o nazwie TY, Wydawnictwo Poligraf, Brzezia Łąka 2017. Burell G., Morgan G., Sociological Paradigms and Organizational Analysis, Heinemann, London 1979.

Chomsky N., The Universal Man, „New Scientists” 2012, nr 213, s. 28-29.

Drozdowicz J., Decydujący moment w świecie Instagramu. Wspótczesna fotografia uliczna $i$ wirtualne tożsamości, [w:] Z. Melosik, M.J. Szymański (red.), Tożsamość w warunkach zmiany społecznej, Wydawnictwo APS, Warszawa 2016, s. 227-238.

Dumas T.M., Maxwell-Smith M., Davis J.P., Giulietti P.A., Lying or Longing for Likes? Narcissism, Peer Belonging, Loneliness and Normative versus Deceptive Like-Seeking on Instagram in Emerging Adulthood, „Computers in Human Behavior” 2017, nr 71, s. 1-10.

Dunin-Wilczyński S., Tradycyjne dziennikarstwo a Instagram, „Biuletyn Informacji Medialnej” 2014, nr 1, s. 33-43.

Dziekanowski C., Klątwa Narcyza, [w:] J. Sieradzan (red.), Narcyzm, Wydawnictwo Uniwersytetu w Białymstoku, Białystok 2011, s. 326-329.

Engelking W., Instagram kiczu, Instagram zbrodni, „Nowe Media” 2014, nr 7/14, s. 86-93.

Gawanowska M., Marka osobista bez tajemnic, Monika Gawanowska Copyright, Białystok 2017.

Goban-Klas T., Cywilizacja medialna. Geneza, ewolucja, eksplozja, Wydawnictwa Szkolne i Pedagogiczne, Warszawa 2005.

Godzic W., Znani z tego, że sa znani. Celebryci w kulturze tabloidów, Wydawnictwa Akademickie i Profesjonalne, Warszawa 2007.

Hill K., 10 Reasons Why Facebook Bought Instagram, www.forbes.com/sites/kashmirhill/ 2012/04/11/ten-reasons-why-facebook-bought-instagram/\#4fed69c4d1b1 (dostęp: 10.07. 2018).

${ }^{63}$ M. Kleemans, S. Daalmans, I. Carbaat, D.J. Anschutz, Picture Perfect..., dz. cyt., s. 93-110; M. Tiggemann, M. Zaccardo, Strong Is the New Skinny..., dz. cyt., s. 1003-1011. 
Hochman N., Schwartz R., Visualizing Instagram: Tracing Cultural Visual Rhythms, [w:] D. Archambault, E. Kandogan, M. Harrigan (eds.), AAAI Technical Report Social Media Visualization, The AAAI Press, Palo Alto 2012.

Ho Moon J., Lee E., Lee J.A., Choi T.R., Sung Y., The Role of Narcissism in Self-Promotion on Instagram, „Personality and Individual Differences” 2016, nr 101, s. 22-25.

Hu Y., Manikonda L., Kambhampati S., What We Instagram: A First Analysis of Instagram Photo Content and User Types, [w:] E. Adar, P. Resnick (eds.), The Eighth International AAAI Conference on Weblogs and Social Media, The AAAI Press, Palo Alto 2014, s. 595-598.

Kacprzyk S.K., Leppert R., Związki miłosne w sieci, Impuls, Kraków 2013.

Kawasaki G., Fitzpatrick P., Jak cię widza, tak cię piszą. Sztuka autopromocji w mediach społecznościowych, tłum. M. Gutowski, Helion, Gliwice 2016.

Kleemans M., Daalmans S., Carbaat I., Anschutz D.J., Picture Perfect: The Direct Effect of Manipulated Instagram Photos on Body Image in Adolescent Girls, „Media Psychology” 2018, nr 21, s. 93-110.

Kreft J., Ewolucja strategii transmedialnych korporacji transnarodowych, Wydawnictwo Uniwersytetu Gdańskiego, Gdańsk 2012.

Królik G., Autoprezentacja, Wydawnictwo Akademii Ekonomicznej, Katowice 2002.

Lasch C., Kultura narcyzmu. Amerykańskie życie w czasach malejących oczekiwań, tłum. G. Ptaszek, A. Skrzypek, Wydawnictwo Akademickie SEDNO, Warszawa 2015.

Michalewski K., Autoprezentacja i prezentacja w mediach, [w:] B. Kudra, E. Olejniczak (red.), Komunikowanie publiczne. Zagadnienia wybrane, Wydawnictwo Uniwersytetu Łódzkiego, Łódź 2014, s. 75-86.

Mierzwa J., Jurjewicz H., Does Facebook, Twitter, Instagram Influence Well-Being and Self-Esteem among Early Adolescents?, „Studia Socialia Cracoviensia” 2016, nr 1(14), s. 137-152.

Nierenberg B., Zarządzanie mediami. Ujęcie systemowe, Wydawnictwo Uniwersytetu Jagiellońskiego, Kraków 2013.

Number of Monthly Active Instagram Users from January 2013 to June 2018 (in Millions), The Statistical Portal, www.statista.com/statistics/253577/number-of-monthly-active-instagram-users/ (dostęp: 14.06.2018).

Pittman M., Reich B., Social Media and Loneliness: Why an Instagram Picture May Be Worth More than a Thousand Twitter Words, „Computers in Human Behavior” 2016, nr 62, s. $155-167$.

Rainie L., Brenner J., Purcell K., Photos and Videos as Social Currency Online, www.pewinternet.org/2012/09/13/photos-and-videos-as-social-currency-online/ (dostęp: 10.07.2018).

Rosey D., Instagram Reaches a Billion Users - And Other Things We Learnt from Boss Kevin Systrom, www.bbc.com/news/newsbeat-44553659 (dostęp: 20.06.2018).

Sasińska-Klas T., Swoistość zjawisk w komunikacji medialnej i problemy w ich badaniach empirycznych, „Studia Medioznawcze” 2014, nr 1(56), s. 13-22.

Sontag S., O fotografii, tłum. S. Magala, Wydawnictwa Artystyczne i Filmowe, Warszawa 1986.

Stępowski R., Jak osiagnnąc sukces. Jak zbudować swoją markę osobistą i sprawić, by firma osiagnęła sukces, Wydawnictwo Roster, Rawa Mazowiecka 2015.

Sung Y., Lee J.-A., Kim E., Choi S.M., Why We Post Selfies: Understanding Motivations for Posting Pictures of Oneself, „Personality and Individual Differences” 2016, nr 97, s. 260-265.

Szarota P., Od Facebooka do post-przyjaźni, Instytut Psychologii. Polska Akademia Nauk, Warszawa 2018.

Szpunar M., Imperializm kulturowy internetu, Instytut Dziennikarstwa, Mediów i Komunikacji Społecznej Uniwersytetu Jagiellońskiego, Kraków 2017.

Szpunar M., Kultura cyfrowego narcyzmu, Wydawnictwa AGH, Kraków 2016. 
Szpunar M., Medialna widoczność jako emanacja hiperobecności, „Zeszyty Prasoznawcze” 2017, nr 3 (231), s. 494-504.

Thumin N., Self-Represtation and Digital Culture, Palgrave Macmillan, Basingstoke 2015.

Tiggemann M., Zaccardo M., Strong Is the New Skinny: A Content Analysis of \#fitspiration Images on Instagram, „Journal of Health Psychology” 2016, nr 23(8), s. 1003-1011.

Top 100 Instagram Users by Followers, https://socialblade.com/instagram/top/100/followers (dostęp: 10.06.2018).

Weiser E.B., \#Me: Narcissism and Its Facets as Predictors of Selfie-Posting Frequency, „Personality and Individual Differences" 2015, nr 86, s. 477-481.

Zimek K., Miłość cienia: interpretacja mitu o Narcyzie w erotyku „Do Kasie” i rękopisu Zamoyskiego, „Pamiętnik Literacki” 2003, nr 94/4, s. 5-26. 